\title{
Adsorption of Diuron and Linuron in Gaza Soils
}

\author{
Yasser El-Nahhal, Mohamed Abadsa, Samir Affifi \\ Department of Earth and Environmental Sciences, The Islamic University of Gaza, Gaza, Palestine \\ Email: y_el_nahhal@hotmail.com
}

Received May 18, 2013; revised June 17, 2013; accepted July 5, 2013

Copyright (c) 2013 Yasser El-Nahhal et al. This is an open access article distributed under the Creative Commons Attribution License, which permits unrestricted use, distribution, and reproduction in any medium, provided the original work is properly cited.

\begin{abstract}
This study investigated the adsorption potential of diuron and linuron in selected soil samples collected from agricultural area of Gaza Strip, Palestine and correlated the adsorption results to the soil properties. The adsorption experiments are based on the batch equilibrium technique and UV-Spectrophotometer method to determine the equilibrium concentration of both herbicides. Results of adsorption experiment showed that linuron and diuron are adsorbed in various amounts in Gaza soils according to the variation in $\mathrm{pH}$, organic matter and clay content. Adsorption isotherms of both herbicides were linear in the tested concentration. Fitting the adsorption data to Freundlich equation showed good fitting and Freundlich constants were less than one indicating physical adsorption processes. It is concluded that soil organic matter and $\mathrm{pH}$ affect the adsorption of both herbicides. These results provided a better understanding of the behavior of diuron and linuron in Gaza soils.
\end{abstract}

Keywords: Adsorption; Diuron; Linurn; Soil; Gaza

\section{Introduction}

Diuron and Linuron are phenylurea herbicides widely used in the world to control annual weeds [1]. The amount used in Gaza Strip Palestine, progressively increased in the past ten years [2]. This situation may have led to groundwater contamination. However, recent studies indicate toxicity to cyanobacteria [3], and Fish [4]. Several trials have been made to reduce environmental contamination [5-7]. These studies are based on adsorbing the herbicides to organo-clay complexes. This process restricts the leaching potential of pesticides. However, it is still important to understand the adsorption behavior of herbicides in soil. Chiristen et al. [8] and Nkedi-Kizza et al. [9] studied the adsorption behavior of phenylurea herbicides in different soils and reported that organic carbon was the main factor affecting urea sorption. Chaplain et al. [10] reported that soil hydrophobicity was an important factor for diuron adsorption in soils. Whereas, several researchers [11-13] reported that the adsorption of linuron was significantly correlated with soil organic matter and clay content. Haouari et al. [12] found that the adsorption of diuron and linuron in clayey soils in Morocco fitted the Freundlich equation. Furthermore, Yihua Liu et al. [14] studied the adsorption-desorption behaviors of diuron investigated in six cultivated soils of China and reported that diu- ron adsorption on soil was at a rather high level under low $\mathrm{pH}$ value conditions and decreased with increasing $\mathrm{pH}$ value. Moreover, Jianhua et al. [15] studied the adsorption kinetics of diuron from aqueous solutions onto activated carbon fiber, and showed the formation of hydrogen bonding between diuron and water, and temperature variations may possibly affect the adsorption process. This study investigated the adsorption behavior of linuron and diuron in selected soils from Gaza Governorates.

\section{Materials and Methods}

Technical Diuron and Linuron (purity $=99 \%$ ) were purchased from Sigma-Aldrich company in Germany. Physicochemical properties of the tested compounds are shown in Table 1. Technical Diuron and Linuron (purity $=99 \%$ ) were purchased from Sigma-Aldrich company in Germany.

\subsection{Soil Sampling}

The soil samples were collected from top soils $(0-30 \mathrm{~cm})$ of three agricultural locations in Gaza governorates (Khanyounis Governorate, Middle Governorate and North Gaza Governorate). The samples were transferred to a plastic bag, air-dried, sieved through $2 \mathrm{~mm}$, and stored in well-closed plastic bottles in the laboratory. Site descrip- 
tion, identification data and coordinates were recorded as shown in the Table 2.

\subsection{Determination of Soil Texture}

The soil texture expresses the proportions of the various size classes (clay $<0.002 \mathrm{~mm}$, silt $0.002-0.02 \mathrm{~mm}$ and sand $0.02-2.0 \mathrm{~mm}$ particle size). The proportions of these fractions were determined by Hydrometer method using ASTM 152-H hydrometer [16].

\subsection{Determination of Soil $\mathrm{pH}$}

Soil $\mathrm{pH}$ values were measured potentiometrically in a 1 : 2.5 soil-water suspension. Twenty grams of a driedsieved soil were transferred into $200 \mathrm{ml}$ beaker. $50 \mathrm{ml}$ of distilled water were added while stirring for one hour using Electric magnetic stirrer. The $\mathrm{pH}$ meter was calibrated using $\mathrm{pH}$ buffer 4.0, 7.0 and 9.0, and then the $\mathrm{pH}$ of suspension was measured according to previous report [17].

\subsection{Electrical Conductivity (EC)}

Electrical conductivity (EC) of soil was measured potentiometrically in a 1: 2.5 soil-water suspensions. Twenty grams of an oven dried-sieved soil were weighed, transferred into $200 \mathrm{ml}$ beaker. $50 \mathrm{ml}$ of distilled water were added while stirring for one hour using Electric magnetic stirrer. The Electrical conductivity meter was calibrated using Standard potassium chloride $(\mathrm{KCl})$ solutions 0.01 and $0.1 \mathrm{M}$ and then the EC of filtrate were measured, Unit of measurement dS/m [18].

\subsection{Determination of the Organic Matter}

The organic carbon content in the soils used were analyzed in Ministry of Agriculture in Gaza using Walkley-Black method [19]. The organic carbon in the sample is oxidized with potassium dichromate and sulfuric acid. The excess potassium dichromate is titrated against ferrous ammonium sulfate. One gram soil was weighed and transferred into $500 \mathrm{~mL}$ conical flask. $10 \mathrm{~mL}$ of $1 \mathrm{~N}$ $\mathrm{K}_{2} \mathrm{Cr}_{2} \mathrm{O}_{7}$ and $20 \mathrm{~mL}$ of conc. $\mathrm{H}_{2} \mathrm{SO}_{4}$ were added. Swirled carefully then let to stand for 30 minutes. $200 \mathrm{~mL}$ distilled water and $10 \mathrm{~mL} \mathrm{H}_{3} \mathrm{PO}_{4}$ were slowly added. Then 1 $\mathrm{mL}$ of diphenylamine indicator was added and the resulted suspension was titrated against $0.5 \mathrm{~N}$ ferrous ammonium sulfate solution until green color started to appear indicating the end point. Blank must run simultaneously.

\subsection{Adsorption Experiments}

Stock solution of diuron/linuron was prepared by dissolving $30 \mathrm{mg}$ active ingredient in 2 - $3 \mathrm{~mL}$ methanol and diluting to $1 \mathrm{~L}$ with deionised water. The low concentration of methanol in the adsorption experiments had no influence on herbicide adsorption [20]. The adsorption of diuron/ linuron on soil was measured at room temp. $\left(25^{\circ} \mathrm{C} \pm 2^{\circ} \mathrm{C}\right)$. Appropriate aliquots of the aqueous stock solution of a diuron/linuron was diluted with distilled water to $25 \mathrm{~mL}$ and added to $50 \mathrm{mg}$ soil in $30-\mathrm{mL}$ centrifuge tubes. The concentration of diuron/linuron ranged between $1.2 \mathrm{mg} / \mathrm{L}$ and $31 \mathrm{mg} / \mathrm{L}$. The final concentration of soil was $1 \mathrm{~g} / \mathrm{L}$. The dispersions were kept under continuous agitation during 48 hours. The supernatant was

Table 1. Physicochemical properties of the tested compounds.

\begin{tabular}{lll}
\hline Physical Properties & Diuron & Linuron \\
\hline Chemical Name & N-(3,4-dichlorophenyl)-N,N-dimethyl urea & 3-(3,4-dichlorophenyl)-1-methoxy-1-methylurea \\
Molecular Weight & 233.10 & 249.11 \\
Water Solubility & $42 \mathrm{mg} / \mathrm{L}$ & $81 \mathrm{mg} / \mathrm{L}$ \\
Vapor Pressure & $0.41 \mathrm{mPa}$ & $2 \mathrm{mPa}$ \\
Partition Coefficient $\left(\mathrm{K}_{\mathrm{OW}}\right)$ & 2.6 & 3.0043 \\
\hline
\end{tabular}

Table 2. Sampling sites identification information.

\begin{tabular}{|c|c|c|c|c|}
\hline \multirow{2}{*}{ Site } & \multirow{2}{*}{ City } & \multirow{2}{*}{ Prominent Mark } & \multicolumn{2}{|c|}{ GPS Coordinates } \\
\hline & & & $\mathrm{N}$ & $\mathrm{E}$ \\
\hline 1 & Kh. Y & Alsouraje Street & $31,22,150$ & $34,20,656$ \\
\hline 2 & Middle zone & Elberka Street & 31, 24, 905 & $34,20,243$ \\
\hline 3 & North Zone & Safe Agricultural Society & $31,22,102$ & $34,31,493$ \\
\hline
\end{tabular}


separated by centrifugation at 20,000 g for $0.5 \mathrm{~h}$.

The concentration of herbicide in the supernatants was determined by UV-spectrophotometer, (CT-220 Spectrophotometer), the wavelengths of the absorbance of diuron are $247 \mathrm{~nm}$ and for linuron is $246 \mathrm{~nm}$ according to previous report [21].

Linear regression was used to determine the equilibrium concentration of herbicide solutions. The regression showed $\mathrm{R}^{2}$ value close to unity (0.9992). The amount of linuron, diuron adsorbed was calculated from the depletion of the linuron concentration by adsorption according to Equation (3.2) El-Nahhal and Safi [22].

$$
\begin{gathered}
C_{i} V=C_{e} V+M S \\
S=\left(C_{i}-C_{e}\right) V / M
\end{gathered}
$$

where $C_{i}$ is the initial concentration of herbicide, and $C_{e}$ is the remaining concentration of the herbicide in the solution in $\mathrm{mg} / \mathrm{L}, V$ is the volume of the solution in litter, $S$ is the concentration of the herbicide in the solid phase $\mathrm{mg} / \mathrm{g}$ (the adsorbed amount), and $M$ is the mass of soil in gram.

For each isotherm, a reference solution with an intermediate concentration was stirred without soil to evaluate adsorption on the glass or other losses. All adsorption experiments were made in duplicate samples with a control.

\subsection{Standard Curve}

Stock solution of diuron and linuron was diluted in $1 \mathrm{ml}$ of grade methanol and then diluted in water to a concentration of 38 ppm diuron and 35.4 ppm of linuron as a working standard. A series of linuron standards of, 0.00, 0.56, 2.26, 7.08, 14.16 and 21.24 ppm were prepared. The absorbance was measured spectrophotometrically at $246 \mathrm{~nm}$. A series of diuron standards of $0.00,0.506$, 1.518, 3.036, 12.144, and $24.288 \mathrm{ppm}$, were prepared. The absorbance measured spectrophotometrically at 247 nm.

\subsection{Statistical Analysis}

The growth inhibition data was analyzed for variance, and main effects and interactions was tested for signifi- cance using repeated measures ANOVA. Univariate comparisons of mean growth inhibition at different depths were performed by T-test ( $\alpha=0.05)$, the statistical analysis was performed by using Microsoft Excel software.

\section{Results and Discussion}

\subsection{Soil Properties}

Properties of soil used in this study are shown in Table 3. It can be seen that $\mathrm{pH}$ values of the tested soils range between 7.32 and 8. Furthermore the EC values range from 1.81 and $2.63 \mathrm{dS} / \mathrm{m}$, the total organic matter range from $0.801 \%$ and $0.254 \%$. This indicates that the soil is nearly poor with organic matters. The clay fraction of soils range between $10 \%$ and $47 \%$. The Characteristics of used soil are shown in Table 3.

\subsection{Adsorption Isotherm of Linuron}

The relationship between the Optical Density (OD) and low concentration of Diuron and linuron showed linear relationship (Data not shown) with $\mathrm{R}^{2}$ values of 0.9997 and 0.997 diuron and linuron respectively. These results indicate strong positive association. Accordingly, the regression equations of linear relationship of Diuron $(\mathrm{Y}=$ $0.082 \mathrm{X})$ and linuron $(\mathrm{Y}=0.0827 \mathrm{X})$ were used to determine the remaining concentration of the corresponding compound in the aqueous solution in the adsorption experiment. Y and X represent OD and the remaining concentration respectively. Results of the control of adsorption experiments indicate no changes in the initial concentration of linuron and diuron in the glass tube that did not contain soil in the adsorption. Explanation of these results suggests that the glass tube used for adsorption experiment has no capacity to adsorb the herbicides. Accordingly, the disappearance of linuron or diuron in the experiment is due to the adsorption in the soil fraction. EL-Nahhal and Safi, [22] found similar results for other cases.

\subsection{Adsorption of Diuron}

Figure 1 presented the plot of adsorption of diuron in

Table 3. Soils characteristics.

\begin{tabular}{cccccccccc}
\hline Site & $\mathrm{pH}$ & EC dS/m & OM\% & TOC\% & Sand\% & Silt\% & Clay\% & Tex \\
\hline Kh. Y & 8 & 1.59 & 0.76 & 0.44 & 62.5 & 17.5 & 20 & SL \\
MZ & 7.32 & 1.81 & 0.25 & 0.15 & 87.5 & 1.25 & 11.3 & LS \\
NZ & 7.33 & 2.36 & 0.57 & 0.33 & 60 & 12.5 & 27.5 & C \\
Clay soil & 7.36 & 2.63 & 0.80 & 0.47 & 23 & 30 & 47 & CS \\
\hline
\end{tabular}

SL, LS, C and CS stand for sand loamy, loamy sand, clay and clay silt respectively. 


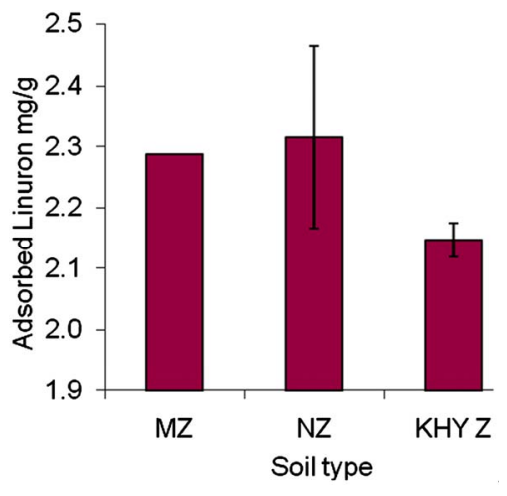

Figure 1. Adsorption of linuron in different soils. Error bars represent standard deviation.

various soils from Gaza Governorates; it appears that the adsorbed amount in North Gaza (NZ) Governorate soil is the highest among the selected soils. This can be explained by the fact that NZ soil has the highest clay fractions (27.3\%) and organic matter (0.571\%), followed by Khanyounis Governorate (KHYZ) soil which has the second highest clay mineral content (20\%) and has the highest organic matter content $0.762 \%$ (Table 3).

The adsorbed amounts in NZ and KHYZ soil are higher than that of Middle Zone (MZ). This probably is due to the high organic matter and clay fraction (Table 3), this probably is due to cation exchange capacity in the clay.

Clay and organic matter are often intimately associated; a previous report found that the organic matter was the key adsorbent for diuron $([23,24]$. Afifi and Abu-Swareh, [25] found that the organic matter in Gaza soils play an important role in the adsorption of chemicals. Adsorption isotherm of diuron in Kh.Y soil is shown in Figure 2.

It can be seen that the adsorption of diuron increases as its concentration in the equilibrium solution is increased, indicating strong positive correlation.

\subsection{Adsorption of Linuron}

Adsorptions of linuron in various soils from Gaza are presented in Figure 3. It appears that the adsorbed amount in NZ, and Kh.Y soil is higher than that of MZ, this probably is due to the high organic matter and clay fraction (Table 3). A previous report found that adsorption of linuron was significantly correlated with soil organic matter $[11,13]$. The soil of Kh.Y and NZ have high fraction of organic carbon $0.442 \%$ and $0.331 \%$ respectively (Table 3). This indicates that organic carbon was the main factor affecting linuron adsorption. Similar observation was previously reported [8]. Adsorption of linuron in the North Governorate and in the Khanyounis are nearly similar degrades less to the high value of error bars. The explanation of this results is that both soils have close $\mathrm{pH}$ values making the ionization fraction are similar.

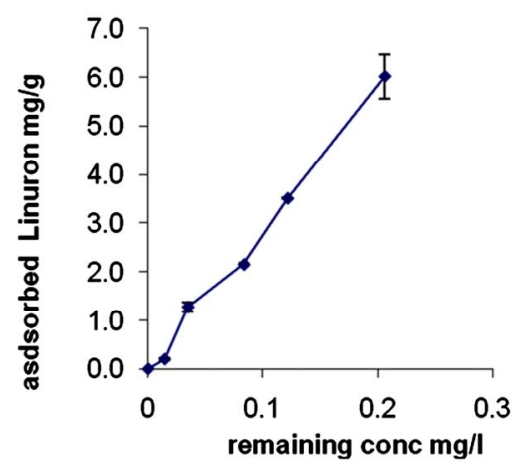

Figure 2. Adsorption isotherm of linuron on Kh.Y soil. Error bars represent standard deviation.

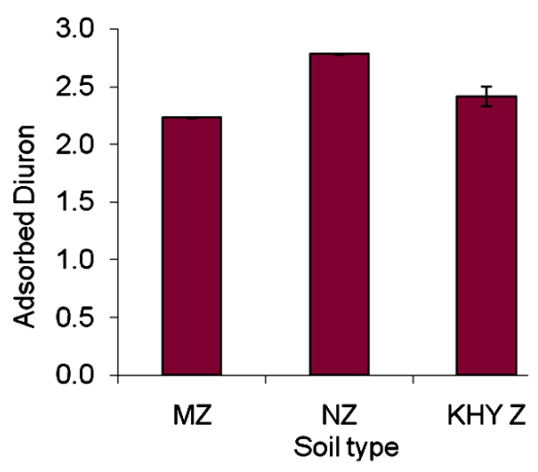

Figure 3. Adsorption of diuron on different soils in Gaza.

Accordingly, similar amount of adsorbed linuron were observed. Adsorption isotherm of linuron in Kh.Y soil is shown in Figure 4. The adsorbed amount increased with increasing the concentration of linuron. Application of linear regression appears best fit in the relationship between points and $R^{2}$ value equals to 0.99 indicating strong positive association. This suggests high affinity of these soil samples for linuron at low herbicide concentrations. It appears that the adsorbed amount is very little $(0.6 \%)$ the explanation of this result is that linuron has hydrophobic nature and the soil is more hydrophilic due to the presence of organic cations in soil (Table 3), a previous report found same results in other case [21]. Nevertheless, the adsorbed amount of linuron increased linearly as the concentration increased, probably due to the high presence of clay fraction in soil (Table 3). EL-Nahhal \& Lagely [20] found similar phenomena for the adsorption of linuron in Bentonite clays, Sorensen et al., [13] found that the linuron is bound to soil (especially clay) and organic matter and does not move freely.

\subsection{Classification of Adsorption Isotherms}

Adsorption isotherm of Diuron (Figure 2) and linuron (Figure 4) can be classified as L-type according to the classification of Giles et al., [26]. It was stated that the magnitude of the exponent $1 / n$ gives an indication of the 
favorability and capacity of the adsorbent/adsorbate system. The soils of Kh.Y showed L-type isotherm $(1 / n>1)$, which indicates that Diuron/linuron is adsorbed on the clay fraction of soil, besides organic matter. Our results agreed with previously $[10,23]$ who produced similar results with other soils. Furthermore, the low adsorption of diuron in Kh. Y soil (Figure 2) is probably due to high $\mathrm{pH}$ in Kh.Y soil (Table 3). It may be suggested that at high $\mathrm{pH}$ value Diuron becomes an anion, in this case repulsion forces between clay surfaces and diuron reduced the adsorption. Under this condition, the organic fraction in soil is the main adsorbent. At low $\mathrm{pH}$ value Diuron may become a proton and higher adsorbed amount may be observed. This statement is strongly supported by ElNahhal and Safi [22] and Yihua liu et al., [14] who found that the adsorption of diuron on the selected soils were rather high at low $\mathrm{pH}$ values and decreased with the increasing $\mathrm{pH}$ values of the suspension.

Fitting the data of Diuron (Figure 1) and linuron (Figure 4) to Freundlich equation show linear relationship with $\mathrm{R}^{2}=0.9978$ and 0.9873 respectively. Both herbicides have low $\mathrm{K}$ and $\mathrm{n}$ values (Table 4). These results indicate physical interaction between Diuron/linuron and clay or soil organic matter fraction.

The low value of $n(<1)$ indicates physical adsorption and monolayer adsorption.

The isotherm is of type $\mathrm{L}$ according to the previous classification [26], which shows the adsorption curve for diuron in clay soil at relatively low range of equilibrium concentration. This low concentrations range is prompted by the low solubility of diuron, the adsorption curve for clay soil show initial slight increase in adsorption with increase in concentration.

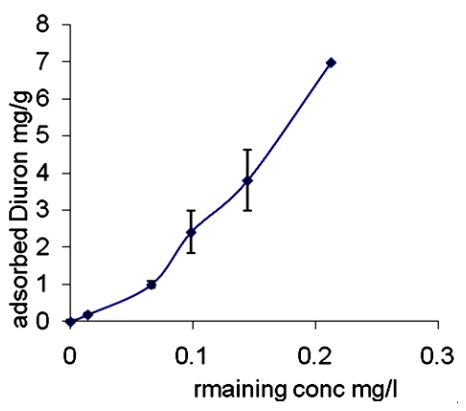

Figure 4. Adsorption isotherm of dinuron on Kh.Y soil. Error bars represent standard deviation.

Table 4. Freundlich constants for diuron and linuron for $\mathrm{Kh}$. Y soil.

\begin{tabular}{lccc}
\hline & \multicolumn{3}{c}{ Khanyounis soil } \\
\cline { 2 - 4 } Herbicide & $\mathrm{k}$ & $\mathrm{n}$ & $\mathrm{r}^{2}$ \\
\hline Diuron & 49.2 & 0.752 & 0.986 \\
Linuron & 50.82 & 0.77 & 0.997 \\
\hline
\end{tabular}

Comparing the adsorption of Diuron and linuron in Kh.Y soils, it can be seen that Diuron is adsorbed more than linuron. This may be due to the hydrophobic factor. It is obvious that diuron has lower Kow value than linuron (Table 1) indicating less hydrophobic tendency. A number of researchers have hypothesized additional site-specific interactions between the polar groups of the organic compounds and charges on the mineral surface [27].

\section{Conclusions}

This study presents an attempt to understand the adsorption potential of Diuron and linuron in selected soil from Gaza Governorate, Palestine. Our idea in this study provides a better understanding to the behavior of herbicides in Gaza Soils. The study is based on the following approach:

1) The first step is to collect soil samples from different agricultural area and to characterize the physicochemical properties of soil and to correlate them with the adsorption results.

2) The second step is to understand the adsorption behavior using batch equilibrium technique and spectrophotometer to determine the equilibrium concentrations of the tested herbicides.

The adsorbed amount of Diuron and linuron is moderate in all soils. The adsorption isotherms of both herbicides were best fit to Freundlich equation with $r^{2}$ values equal to 0.99 for both herbicides. The physical adsorption parameter was less than "one” for all cases. Generally the adsorption of those herbicides was poor in most soils and considerably affected by three factors:

1) Clay fraction is negatively charged and exchange cations are present, they can influence the adsorption of ionic molecules by ion exchange.

2) Soil pH.

3) Soil organic matter which acts as a non-polar phase or surface and consequently is the main sorbent for diuron and linuron.

\section{Acknowledgements}

Dr Y. El-Nahhal acknowledges Alexander von Humboldt Stiftung/Foundation Fellowship Grant no IV-PAL/ 1104842 STP, Germany.

\section{REFERENCES}

[1] C. D. Tomlin, “The Pesticides Manual," 11th Edition, Britich Crop Protection Council, 2000.

[2] Ministry of Agriculture, “Annual Report,” Palestinian National Authority, Ram Allah, PNA, 2010.

[3] S. Kerkez, "Eco-Toxicity of Diuron, Dequat and Terbutryn as Single and Mixtures to Cyanobacterial Mats,” M.Sc. Thesis, The Islamic University of Gaza, Gaza, 2013. 
[4] Sh. EL-Njjar, "Eco-Toxicity of Carbaryl, Chlorpyrifos, and Diuron, as Individual and in Mixtures on Daphnia magna and Tilapia nilotica," MSc Thesis, The Islamic University-Gaza, Gaza, 2013.

[5] Y. El-Nahhal, S. Nir, S. Serban, O. Rabinowitz and B. Rubin, "Organoclay Formulation of Acetochlor for Reduced Movement in Soil," Agricultural and Food Chemistry, Vol. 49, No. 11, 2001, pp. 5371-5464. doi:10.1021/jf010561p

[6] G. Lagaly, "Introduction: Pesticide-Clay Interactions and Formulations,” Applied Clay Science, Vol. 18, No. 5-6, 2001, pp. 205-209. doi:10.1016/S0169-1317(01)00043-6

[7] G. Rytwo, Y. Gonen, S. Afuta and S. Dultz, "Interaction of Pendimethalin with Organo-Montmorillonite Complexes,” Applied Clay Science, Vol. 28, No. 1-4, 2005, pp. 67-77. doi:10.1016/j.clay.2004.01.016

[8] C. M. Fouquk-Brouard and J. M Fournier, “AdsorptionDesorption and Leaching of Phenylurea Herbicideson Soils,” Talanta, Vol. 43, No. 10, 1996, pp. 1793-1802.

[9] P. Nkedi-Kizza, P. C. Rao and J. W. Johnson, “Adsorption of Diuron and 2,4,5-T on Soil Particle-Size Separates,” Environmental Quality, Vol. 12, No. 2, 1983, pp. 195-197. doi:10.2134/jeq1983.00472425001200020009x

[10] V. Chaplain, A. Brault, D. Tessier and P. Defossez, "Soil Hydrophobicity: A Contribution of Diuron Sorption Experiments,” Soil Science, Vol. 59, No. 6, 2008, pp. 12021208. doi:10.1111/j.1365-2389.2008.01080.x

[11] M. Sánchez-Camazano, M. J. Sánchez-Martín and R. Delgado-Pascual, "Adsorption and Mobility of Linuron in Soils as Influenced by Soil Properties, Organic Amendments, and Surfactants," Agriculture and Food Chemistry, Vol. 48, No. 7, 2000, pp. 3018-3026. doi:10.1021/jf990812i

[12] H. Haouari, A. Dahchour, A. Peña-Heras, X. Louchard, B. Lennartz, M. Elbelghiti Alaoui and A. Satrallah, "Behavior of Two Phenylurea Herbicides in Clayey Soils and Effect of Alternating Dry-Wet Conditions on Their Availability," Environmental Science and Health, Part B, Vol. 41, No. 6, 2006, pp. 883-893.

[13] S. R. Sorensen, J. Rasmussen, C. S. Jacobsen, O. S. Jacobsen, R. K. Juhler and J. Aamand, "Elucidating the Key Member of a Linuron-Mineralizing Bacterial Community by PCR and Reverse Transcription-PCR Denaturing Gradient Gel Electrophoresis 16s rRNA Gene Fingerprinting and Cultivation," Applied and Environmental Microbiology, Vol. 71, No. 7, 2005, pp. 4144-4148. doi:10.1128/AEM.71.7.4144-4148.2005

[14] Y. H. Liu, Z. Z. Xu, X. G. Wu, W. J. Gui and G. N. Zhu, "Adsorption and Desorption Behavior of Herbicide Diuron on Various Chinese Cultivated Soils," Hazardous Materials, Vol. 178, No. 1-3, 2010, pp. 462-468.

[15] J. H. Xu, Y. B. Sun, Z. Y. Li and J. W. Feng, "Kinetic of Diuron Adsorption on to Activated Carbon Carbon Fiber Study," School of Environment, Vol. 2, 2011, pp. 832-
835.

[16] G. J. Bouyoucos, "Hydrometer Method Improved for Making Particle Size Analyses of Soils,” Agronomy Journal, Vol. 54, No. 5, 1962, pp. 464-465. doi:10.2134/agronj1962.00021962005400050028x

[17] S. Dhyan, P. K. Chhonkar and R. N. Pandey, "Soil, Plant and Water Analysis-Amethod Manual,” IARI, New Delhi, 1999.

[18] L. P. Van Reeuwijk, "Procedures for Soil Analysis,” 3rd Edition, International Soil Reference and Information Centre (ISRIC), Wageningen, 1992.

[19] J. T. Sims and A. M. Wolf, "Recommended Soil Testing Procedures for the Northeastern United States," Northeastern Regional Publication No. 493 (Revised), University of Delaware Agricultural Experimental Station, Newark, 1995.

[20] Y. El-Nahhal and G. Lagaly, "Salt Effects on the Adsorption of a Pesticide on Modified Bentonites," Colloid and Polymer Science, Vol. 283, No. 9, 2005, pp. 968-974.

[21] I. Franco, C. Vischetti, M. T. Baca, M. De Nobili, C. Mondini and L. Leita, "Adsorption of Linuron and Metamitron on Soil and Peats at Two Different Decomposition Stages," Soil and Sediment Contamination: An International Journal, Vol. 6, No. 3, 1997, pp. 307-315.

[22] Y. El-Nahhal and J. Safi, "Adsorption of Benzene and Naphthalene to Modified Montmorillonite," Journal of Food, Agriculture and Environment, Vol. 3, No. 2, 2005, pp. 295-298.

[23] A. G. Ahangar, R. J. Smernik, R. S. Kookana and D. J. Chittleborough, "Clear Effects of Soil Organic Matter Chemistry, as Determined by NMR Spectroscopy, on the Sorption of Diuron,” Chemosphere, Vol. 70, No. 7, 2008, pp. 1153-1160. doi:10.1016/j.chemosphere.2007.08.054

[24] P. Wang and A. A. Keller, "Sorption and Desorption of Atrazine and Diuron onto Water Dispersible Soil Primary Size Fractions,” Water Research, Vol. 43, No. 5, 2009, pp. 1448-1456. doi:10.1016/j.watres.2008.12.031

[25] S. Afifi and A. Abu-Swareh, "Adsorption Behaviour of 2,4-Dichlorophenol and 2,4,5-Trichlorophenol on Soil of Gaza Strip,” Bethlehem University, Vol. 18, 1999, pp. 36-54.

[26] C. H. Giles, T. H. Mac Ewan, S. N. Nakhwa, and D. A. Smith, "System of Classification of Solution Adsorption Isotherms, and Its Use in Diagnosis of Adsorption Mechanisms and in Measurement of Specific Surface Areas of Solids," Chemical Society, Vol. 111, 1960, pp. 39733993. doi:10.1039/jr9600003973

[27] G. Y. Sheng, Y. N. Yang, M. S. Huang and K. Yang, "Influence of $\mathrm{pH}$ on Pesticide Sorption by Soil Containing Wheat Residue-Derived Char," Environmental Pollution, Vol. 134, No. 3, 2005, pp. 457-463. doi:10.1016/j.envpol.2004.09.009 